\title{
Fabrication of Fish Gelatin Microfibrous Mats by Solution Blow Spinning
}

\author{
José Luiz Vilches ${ }^{a}$, Men de Sá Moreira de Souza Filho ${ }^{b}$, Morsyleide de Freitas Rosa ${ }^{b}$, Alex Otávio Sanches \\ José Antonio Malmonge ${ }^{a * \text { (D) }}$ \\ ${ }^{a}$ Faculdade de Engenharia, Universidade Estadual Paulista (UNESP), Campus de Ilha Solteira, Ilha Solteira, \\ SP, Brasil \\ ${ }^{b}$ Embrapa Agroindústria Tropical, Fortaleza, CE, Brasil
}

Received: February 21, 2019; Revised: June 30, 2019; Accepted: July 27, 2019

In this work microfiber mats of Nile tilapia (Oreochromis niloticus) gelatin were successfully fabricated by using Solution Blow Spinning technique. The concentration and viscosity of fish gelatin solution, in acid acetic/water $(80 \% \mathrm{v} / \mathrm{v})$, were correleted to the morphology and diameter of the gelatin microfibers. It was found that increased solution viscosity leads to increase of fibers diameters from approximately $280 \mathrm{~nm}$ at viscosity $\sim 0.085$ Pa.s. to approximately $1195 \mathrm{~nm}$ at viscosity $\sim 1.877$ Pa.s. The TG thermograms showed similar thermal profiles for all fibrous mat gelatins with thermal stability at temperatures below $180^{\circ} \mathrm{C}$. The DSC curve showed two endothermic peaks being the second one, in the range of $100-130^{\circ} \mathrm{C}$, strongly influenced by the microfiber diameters. It shifts to higher temperature increasing the microfiber diameter. This behavior was associated to the diffusion of water in the microfibers. Combined DSC/TG results showed a significant influence of the microfiber diameter on the water absorption and desorption process.

Keywords: Fish gelatin, Solution Blow Spinning, Gelatin microfiber, Nile tilapia.

\section{Introduction}

Gelatin has been widely used in food, biomedical, pharmaceuticals, cosmetic and other related fields because of its low cost, biocompatibility, and biodegradability ${ }^{1}$. A natural biopolymer, produced via the partial hydrolysis of native collagen, gelatin has almost identical composition and biological properties as those of collagens ${ }^{1,2}$. Most available gelatins are manufactured from mammalian resources such as pig or cattle bones and skins. With the growth of fish farming there is an increase in the waste (skins, bones and scales) generated by the fish processing industry that could provide a valuable source of gelatin ${ }^{2}$. The use of these waste to produce gelatin would not only contribute to the environment, but would also be an option for people who, for religious reasons and/or other reasons, do not consume gelatin manufactured from mammalian ${ }^{3}$.

The electrospinning is well established technique for polymeric production of micro- and nanofibers ${ }^{4}$. Recently, Medeiros et al. ${ }^{5}$ introduced solution blow spinning (SBS) as a simple alternative to electrospinning. The main advantages of SBS are its low cost, easy implementation, higher fiber production rate and the deposition of fibers onto any type of substrate or collector. In SBS a polymer solution is dragged toward a collector by a gas flow, and the solvent is evaporated during this process, and creates a non-woven mat of polymer micro-and nanofibers, similar to those of the electrospinning technique.
The fiber morphology, such as size, shape, thickness and surface roughness, depends on variables such as carrier gas pressure, solution viscosity, solvent volatility, solution injection rate and polymer type ${ }^{6,7}$.

In this work, SBS was used to produce microfibers mats of gelatin fish obtained from tilapia residue. The samples were characterized by scanning electron microscopy (SEM), U-tube viscometer, thermogravimetry (TG) and differential scanning calorimetry (DSC). Among the results obtained here we highlight the significant influence of the microfibers diameter in the microfibrous mat water absorption.

\section{Material and Methods}

\subsection{Preparation of gelatin}

The gelatin was obtained as described by Silva et al. ${ }^{8}$. Briefly, the tilapia residue (skins, bones and scales) was first washed with watter and then immersed in $\mathrm{NaCl} 0.5 \%$ for $15 \mathrm{~min}$, washed again, immersed in $0.2 \mathrm{~N}$ acetic acid for $45 \mathrm{~min}$, neutralized in $1 \mathrm{M} \mathrm{NaOH}$, and then ground. The ground residue was then submitted to an alkaline treatment $(0.2 \mathrm{~N} \mathrm{NaOH}$ solution on a 1:3 ground residue: $\mathrm{NaOH}$ solution under stirring for $45 \mathrm{~min}$ ), neutralized with $1 \mathrm{M}$ $\mathrm{H}_{2} \mathrm{SO}_{4}$, and centrifuged (Hitachi CR 22GIII) for $5 \mathrm{~min}$ at $2795 \times \mathrm{g}$. The precipitate was weighted and submitted to an acid treatment $\left(0.2 \mathrm{~N} \mathrm{H}_{2} \mathrm{SO}_{4}\right.$ solution on a $1: 3$ precipitate: 
$\mathrm{H}_{2} \mathrm{SO}_{4}$ solution under stirring for $45 \mathrm{~min}$ ), neutralized with $\mathrm{NaOH}$, and centrifuged as described before. Finally the precipitate was then extracted with water at $45^{\circ} \mathrm{C}$ (precipitate: water ratio, 1:5) for $2 \mathrm{~h}$, vacuum filtered through $28 \mu \mathrm{m}$ filter paper, freeze dried, and ground by using an analytical mill (A11 Basic, Ika, Staufen, Germany). The gelatin thus obatined, in powder form, showed the following characteristic: pH 5.45; bloom strength $139 \mathrm{~g}$; protein dry content $72.15 \%$ and ash content, $17.57 \%$.

\subsection{SBS solution preparation}

The gelatin solution for SBS was prepared by dissolving the gelatin powder in acid acetic/water $(80 \% \mathrm{v} / \mathrm{v})$ under magnetic sttiring for 8 hours, being that the first hour the solution was kept at $50^{\circ} \mathrm{C}$ and the remaining time at room temperature. To produce a gelatin microfiber mat, $5 \mathrm{~mL}$ of gelatin solution was placed in a disposable syringe (connected to a $25 \mathrm{G}$ spinal needle) coupled to an injection system. The best conditions for the formation of microfibers were determined and maintained for all the experiments. The injection rate and gas pressure (filtered air) used were $8.1 \mathrm{~mL} / \mathrm{h}$ and $200 \mathrm{kPa}$, respectively. The microfibers were collected in a cylinder (wrapped with teflon foil) with angular velocity and diameter of $70 \mathrm{rpm}$ and $74 \mathrm{~mm}$, respectively. The work distance used was 21 $\mathrm{cm}$ (distance from the needle tip to colector). The gelatin concentration tested were 15, 20 and $25 \% \mathrm{w} / \mathrm{v}$. The gelatin fibrous mats were then stored in desiccator containing silica gel. For the thermal and morphological characterizations, the samples were conditioned for 20 hours in relative humidity of $45 \%$ at room temperature.

\subsection{Characterization}

The morphological structure analyses of obtained microfibers were realized by an EVO LS15- Carl Zeiss Scanning Electron Microscope (SEM). The samples were attached to aluminum stubs with conductive carbon tape and sputtered with gold before the analysis. Fiber diameters were measured by using IMAGE J software (National Institutes of Health, USA), by analyzing 100 random fibers from each image. Shear viscosity tests were performed using a U-tube viscometer with a constant associated to the tube of $\mathrm{k}=0.22$ for FG solutions of 15 and $20 \% \mathrm{w} / \mathrm{v}$ and $\mathrm{k}=0.55$ for solutions of $25 \% \mathrm{w} / \mathrm{v}$.
Thermogravimetric analysis (TA Instruments Model Q600) was conducted in the temperature range of $25-800^{\circ} \mathrm{C}$ at a heating rate of $10^{\circ} \mathrm{C} \cdot \mathrm{min}^{-1}$ in nitrogen atmosphere with a flow rate of $100 \mathrm{~mL} \cdot \mathrm{min}^{-1}$. Approximately $4 \mathrm{mg}$ was used for each sample. DSC analyses (TA Instruments Model DSC25) were performed with a scan rate of $10^{\circ} \mathrm{C} \mathrm{min}^{-1}$ in the temperature range of -10 to $200^{\circ} \mathrm{C}$ under nitrogen atmosphere.

\section{Results and Discussion}

Blow Spinning method proved being an efficient technique to obtain fish gelatin microfibrous mats. To verify the morphology of the mats produced by SBS, the SEM images were taken and are shown in Figure 1. The fibers formed were cylindrical, with a smooth and homogeneous appearance. From the Gaussian distributions following the SEM images, it is observed that the values of the average fibers diameter increase according as the solution concentration increase. For the sample with 15, 20 and $25 \% \mathrm{w} / \mathrm{v}$ concentration of fish gelatin, Figure 1(a), (b) and (c), it is verified mean diameters of 280, 751 and $1195 \mathrm{~nm}$, respectively. It is already well-known that a variety of structures such fibers, beads and ribbons can be reached by using electrospinning technique and the size and shape of these structures are governed by a number of parameters such as polymer solution properties, vapor pressure of the solvent, humidity and also the process parameters such as injection rate and electrical field strength ${ }^{4,9,10}$. These parameters also affect the structure and morphology of the materials produced by SBS, with the exception of the electric field that in the SBS is replaced by gas flow ${ }^{5,6,11}$. In both techniques, the thickness of the fiber was significant influenced by the solution viscosity ${ }^{5-6,10,12-13}$. As viscosity increases, fiber stretching becomes more difficult, and as consequence, thicker fiber are produced. In our case, the thickness of the fibers increased with increasing concentration, and the viscosity tests confirm that an increase on the fish gelatin concentration in acetic acid solvent results in a greater shear viscosity as shown in Table 1 . In our studies, the gas flow and the injection solution rate were fixed. No major changes were observed in the morphology (porous, beads, etc.), demonstrating that the viscosity was the parameter of greatest influence on the fiber diameter. Another interesting result is about productivity of SBS compared with electrospinning.

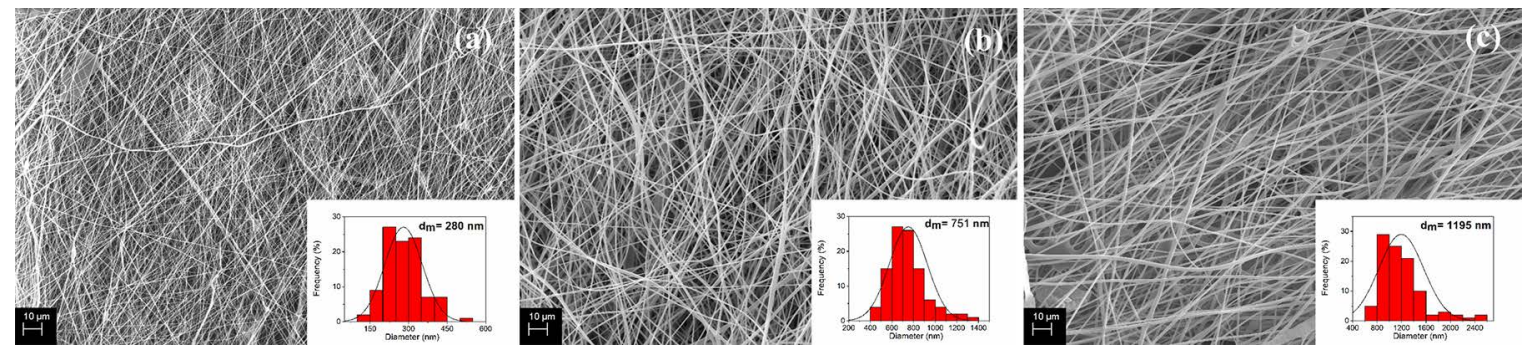

Figure 1. Fish gelatin Microfibers Scanning Electron Microscope (SEM - 1000x zoom) of the sample at varius concentrations: (a) $15 \%$ (w/v); (b) $20 \%(\mathrm{w} / \mathrm{v})$; (c) $25 \%(\mathrm{w} / \mathrm{v})$. 
Table 1. Shear viscosity; $\mathrm{T}_{\mathrm{m}}$ and $\mathrm{T}_{2 \mathrm{ev}}$ obtained from DSC curves; $\%$ water obtained from TG thermograms.

\begin{tabular}{lccc}
\hline Concentration (w/v) & $15 \%$ & $20 \%$ & $25 \%$ \\
\hline Shear viscosity (Pa.s) & 0.08585 & 0.27925 & 1.87752 \\
$\mathrm{~T}_{\mathrm{m}}\left({ }^{\circ} \mathrm{C}\right)$ & 50.7 & 52.1 & 53.3 \\
$\mathrm{~T}_{2 \mathrm{ev}}\left({ }^{\circ} \mathrm{C}\right)$ & 103.9 & 118.2 & 129.4 \\
water $(\%)$ & 7.00 & 5.87 & 4.86 \\
\hline
\end{tabular}

The injection rate used in our experiments was $8.1 \mathrm{~mL} / \mathrm{h}$ which is more than 10 times higher than that used in electrospinning technique for fabrication of fish gelatin microfibers, as reported in the literature ${ }^{10,14-15}$. Thus, for the same gelatin concentration the productivity using SBS will be much higher than using electrospinning.

Figure 2 shows the TG/DTG curves of the microfibers mat samples obtained from different gelatin concentration. TG/DTG curves show three ranges of mass loss: the first located between $30-160^{\circ} \mathrm{C}$ was attributed to the adsorbed water evaporation. According to Correia et al. ${ }^{16}$ mass changes up to $200^{\circ} \mathrm{C}$ are related to the different water forms associated with the gelatine structure. This may be associated on both the surface and inside of triple helix structure by means of hydrogen bonds as well as associated between protein chains ${ }^{16,17}$. The second stage located between $160-260^{\circ} \mathrm{C}$ was attributed to protein degradation ${ }^{16}$, while the third stage, located between $260-800^{\circ} \mathrm{C}$, corresponds to the thermal decomposition of the gelatin ${ }^{16,17}$. Table 1 shows the values obtained for the percentage of water loss found for microfiber mat samples. It was interesting to note that the microfibrous mat samples showed a reduction of the water content with increasing the microfibers diameter. Such behavior was accompanied by the water peak $\left(30-160^{\circ} \mathrm{C}\right)$ shift of maximum temperature to higher temperature. This behavior was associated with water diffusion from internal to external region of the microfibers, which becomes more difficult with the increase of its diameter.

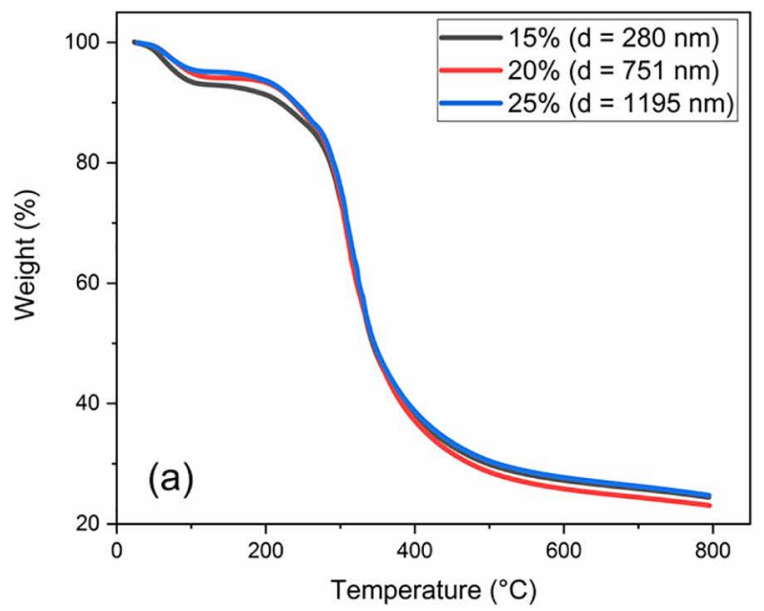

Figure 3 shows the DSC thermogram of the microfiber mat samples with 15,20 and $25 \% \mathrm{w} / \mathrm{v}$. It was possible to observe for the first thermal run, the presence of two endothermic events for all samples (Figure 3a). First heat event located around $50^{\circ} \mathrm{C}$ was attributed to the melting temperature $\left(\mathrm{T}_{\mathrm{m}}\right)$ of fish gelatin; at this temperature occur the transition of the triple helical structure for the coil-like structure (sol-gel) originated by the breakage of hydrogen bonds of the triplehelix structure ${ }^{16-18}$. Higher water content, presented the lowest values of $T_{m}$, fact originated by the plasticizing water effect (Table 1$)^{19}$. The second endothermic event is significantly influenced by the diameter of the microfibers. With maximum temperature peak $\left(\mathrm{T}_{2 \mathrm{ev}}\right)$ in the range of $100-130^{\circ} \mathrm{C}$, it was attributed to the overlap of thermal events such as water evaporation $^{18-21}$ and continues melting and recrystallization of small and imperfect gelatin crystallites ${ }^{20}$. It was observed that the $\mathrm{T}_{2 \mathrm{ev}}$ event tends to overlap with the $\mathrm{T}_{\mathrm{m}}$ event owing to amount of water present in the samples. This effect is more evident for thinner fibers because of its higher contact area. Microfibers with smaller diameters tend to saturate quickly in moist environments, but also facilitate water evaporation owing to the smaller diffusion pathways. The shift of $\mathrm{T}_{2 \mathrm{ev}}$ peak followed the microfiber diameter thickness; the peak shift to higher temperature increasing the fiber diameter. This behavior is linked to the water diffusion in the microfiber that became more difficult for thicker fibers. Due to the complete melting of the gelatin crystallites and water evaporation in the first thermal run, no endothermic peak related to such events were observed in the second thermal run (Figure $3 a)^{22}$.

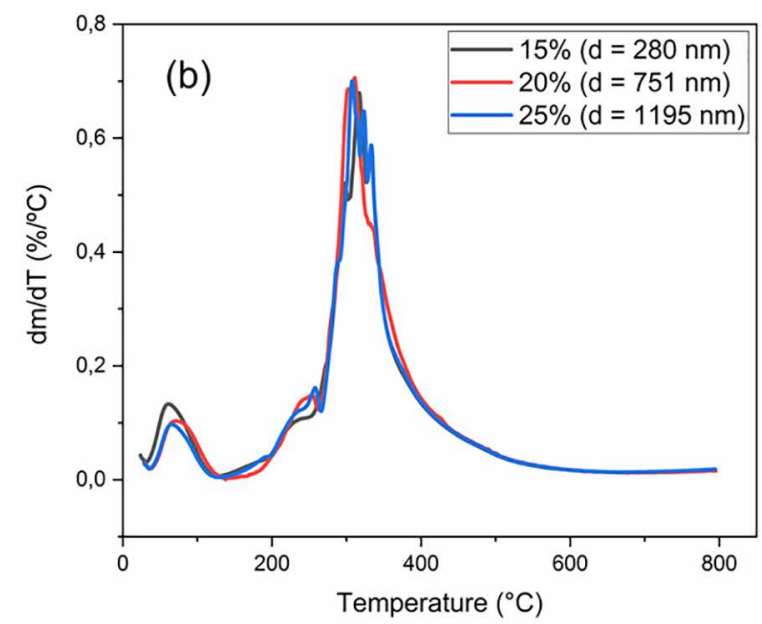

Figure 2. (a)TG and (b) DTG thermograms of microfibrous mat of fish gelatin. 


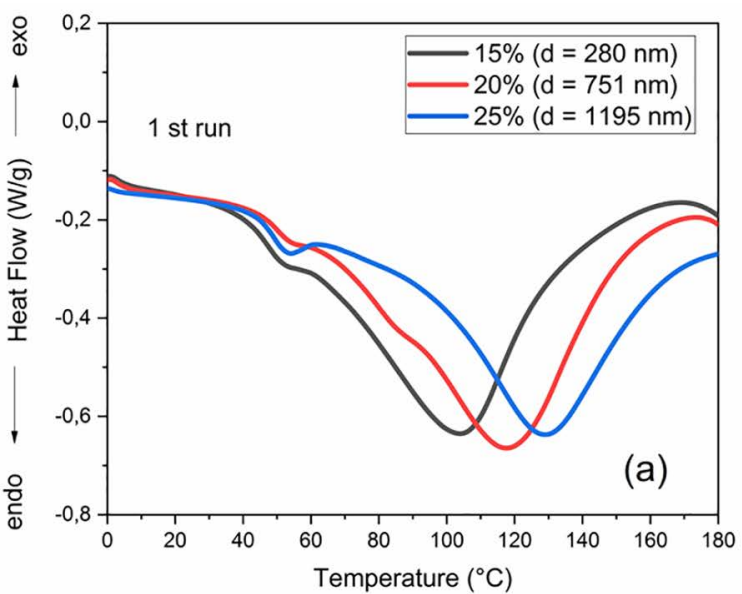

Figure 3. DSC thermograms of microfibrous mat of fish gelatin: run of sample $20 \% \mathrm{w} / \mathrm{v}$.

\section{Conclusions}

The microfiber mats of fish gelatin were produced by Solution Blow Spinning from solutions of gelatin/acetic acid $(80 \% \mathrm{v} / \mathrm{v})$. The concentration of the fish gelatin strongly influenced the microfiber diameter. It was found that increased solution viscosity leads to increase of fibers diameters from approximately $280 \mathrm{~nm}$ at viscosity $\sim 0.085 \mathrm{~Pa}$.s. to approximately $1195 \mathrm{~nm}$ at viscosity $\sim 1.877 \mathrm{~Pa}$.s. TG analysis demonstrates similar thermal profiles for all fibrous mat gelatins obtained from different concentrations, but with different amounts of absorbed water being larger for fibers with larger diameter. DSC curves showed two endothermic peaks being the second one, in the range of $100-130^{\circ} \mathrm{C}$, significantly influenced by the diameter of the microfibers. It shifted from approximately $103.9^{\circ} \mathrm{C}$ for microfibers with $\sim 280 \mathrm{~nm}$ of diameter to approximately $129.4^{\circ} \mathrm{C}$ for microfibers with $\sim 1195 \mathrm{~nm}$ of diameter. This behavior was linked to the water diffusion in the microfiber that became more difficult for thicker ones.

\section{Acknowledgement}

The authors would like to thank Coordenação de Aperfeiçoamento de Pessoal de Nível Superior (CAPES) and Conselho Nacional de Desenvolvimento Científico e Tecnológico (CNPq) for the financial support and scholarship.

\section{References}

1. Boran G, Regenstein JM. Fish Gelatin. Advances in Food and Nutrition Research. 2010;60:119-143.

2. Badii F, Howell NK. Fish gelatin: Structure, gelling properties and interaction with egg albumen proteins. Food Hydrocolloids. 2006;20(5):630-640.

3. Lin L, Regenstein JM, Lv S, Lu J, Jiang S. An overview of gelatin derived from aquatic animals: Properties and modification. Trends in Food Science \& Technology. 2017;68:102-112.

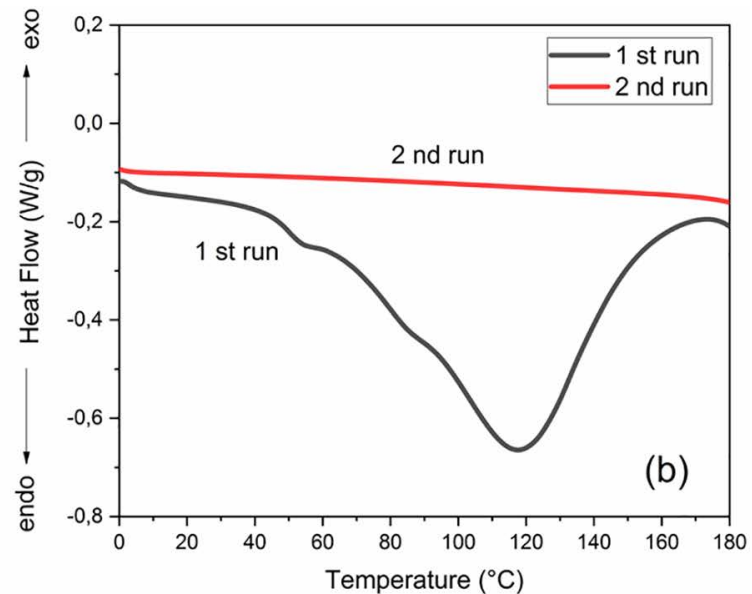

(a) 1 st heating run for all samples and (b) 1 st and 2 nd heating

4. Bhardwaj N, Kundu SC. Electrospinning: A fascinating fiber fabrication technique. Biotechnology Advances. 2010;28(3):325-347.

5. Medeiros ES, Glenn GM, Klamczynski AP, Orts WJ, Mattoso LHC. Solution blow spinning: A new method to produce micro-and nanofibers from polymer solutions. Journal of Applied Polymer Science. 2009;113(4):2322-2330.

6. Oliveira JE, Moraes EA, Costa RGF, Afonso AS, Mattoso LHC, Orts WJ, et al. Nano and submicrometric fibers of poly(D,L-lactide) obtained by solution blow spinning: Process and solution variables. Journal of Applied Polymer Science. 2011;122(5):3396-3405.

7. Li J, Song G, Yu J, Wang Y, Zhu J, Hu Z. Preparation of Solution Blown Polyamic Acid Nanofibers and Their Imidization into polyimide Nanofiber Mats. Nanomaterials (Basel). 2017;7(11):395.

8. Santos TM, Souza Filho MSM, Caceres CA, Rosa MF, Morais JPS, Pinto AMB, et al. Fish gelatin films as affected by cellulose whiskers and sonication. Food Hydrocolloids. 2014;41:113-118.

9. Koombhongse S, Liu W, Reneker DH. Flat polymer ribbons and other shapes by electrospinning. Journal of Polymer Science, Part B: Polymer Physics. 2001;39(21):2598-2606.

10. An K, Liu H, Guo S, Kumar DN, Wang Q. Preparation of fish gelatin and fish gelatin/poly(L-lactide) nanofibers by electrospinning. International Journal of Biological Macromolecules. 2010;47(3):380-388.

11. Cena CR, Silva MJ, Malmonge LF, Malmonge JA. Poly(vinyl pyrrolidone) sub-microfibers produced by solution blow spinning. Journal of Polymer Research. 2018;25:238.

12. Kwak HW, Shin M, Lee JY, Yun H, Song DW, Yang Y, et al. Fabrication of an ultrafine fish gelatin nanofibrous web from an aqueous solution by electrospinning. International Journal of Biological Macromolecules. 2017;102:1092-1103.

13. Nur Hanani ZA, Roos YH, Kerry JP. Use and application of gelatin as potential biodegradable packaging materials for food products. International Journal of Biological Macromolecules. 2014;71:94-102.

14. Deng L, Li Y, Feng F, Zhang H. Study on wettability, mechanical property and biocompatibility of electrospun gelatin/zein nanofibers cross-linked by glucose. Food Hydrocolloids. 2019;87:1-10. 
15. Gomes SR, Rodrigues G, Martins GG, Henriques CMR, Silva JC. In vitro evaluation of crosslinked electrospun fish gelatin scaffolds. Materials Science and Engineering: C. 2013;33(3):1219-1227.

16. Correia DM, Padrão J, Rodrigues LR, Dourado F, Lanceros-Méndez $\mathrm{S}$, Sencadas V. Thermal and hydrolytic degradation of electrospun fish gelatin membranes. Polymer Testing. 2013;32(5):995-1000.

17. Martins MEO, Sousa JR, Claudino RL, Lino SCO, do Vale DA, Silva ALC, et al. Thermal and Chemical Properties of Gelatin from Tilapia (Oreochromis niloticus) Scale. Journal of Aquatic Food Product Technology. 2018;27(10):1120-1133.

18. Fakirov S, Sarac Z, Anbar T, Boz B, Bahar I, Evstatiev M, et al. Mechanical properties and transition temperatures of crosslinkedoriented gelatin. II. Effect of orientation and water content on transition temperatures. Colloid and Polymer Science. 1997;275(4):307-314.
19. Yakimets I, Wellner N, Smith AC, Wilson RH, Fahrat I, Mitchell J. Mechanical properties with respect to water content of gelatin films in glassy state. Polymer. 2005;46(26):12577-12585.

20. Patil RD, Mark JE, Apostolov A, Vassileva E, Fakirov S. Crystallization of water in some crosslinked gelatins. European Polymer Journal. 2000;36(5):1055-1061.

21. Rivero S, García MA, Pinotti A. Correlations between structural, barrier, thermal and mechanical properties of plasticized gelatin films. Innovative Food Science \& Emerging Technologies. 2010;11(2):369-375.

22. Dai CA, Chen YF, Liu MW. Thermal properties measurements of renatured gelatin using conventional and temperature modulated differential scanning calorimetry. Journal of Applied Polymer Science. 2006;99(4):1795-1801. 